\title{
Effects of therapeutic massage on gait and pain after delayed onset muscle soreness
}

\author{
Jun-Ho Han', Min-Jeong Kim² ${ }^{2}$ Hyuk-Jin Yang ${ }^{2}$, Yu-Jin Lee ${ }^{2}$, Yun-Hee Sung ${ }^{1,2 *}$ \\ 'Department of Physical Therapy, Graduate School of Engineering, Kyungnam University, Changwon, Korea \\ ${ }^{2}$ Department of Physical Therapy, College of Natural Science, Kyungnam University, Changwon, Korea
}

Unfamiliar or sudden exercise can induce delayed onset muscle soreness (DOMS) within 12-24 h. So, several researchers have reported various interventions to treat DOMS. Massage is generally known to eliminate muscle fatigue. However, effect of massage after DOMS is still not clear. We investigated whether the massage is effective on pain and gait after DOMS. The participants were divided into a control group $(n=10)$ with DOMS and an experimental group $(n=11)$ with the massage treated after DOMS. We induced DOMS by taking isotonic exercise with going up and down 20 times in 5-story building. We applied the massage and assessment on gastrocnemius of dominant foot. The change of gait and pain was assessed using gaitrite and algometer. In the present results, the massage on gastrocnemius after DOMS showed significant difference in pain $(P<0.05)$. Also, there was a significant difference in gait $(P<0.05)$, especially, spatial parameters (distance, step length, stride length) and temporal parameters (ambulation, heel on off time, stride velocity). Moreover, the pain relief after massage-treated in DOMS correlated with gait. These results suggest that the massage on gastrocnemius after DOMS has influence on pain and gait performance. Therefore, massage can be applied as intervention for delayed onset muscle soreness.

Keywords: Delayed onset muscle soreness, Massage, Gastrocnemius, Gait, Pain

\section{INTRODUCTION}

As the concept of wellness, the idea that people must live healthy as long as they live, received spotlight, not only the young generation, even middle and elderly generation started to enjoy the sports. But sudden exercises or aggressive exercises that do not fit to physical conditions will lead to pain and may even hurt one's health (Kim et al., 2012). Of course, exercises bring several positive effects, but if executed inappropriately or excessively, one will experience muscle pain usually expressed as discomfort or soreness. Like this, after performing unfamiliar exercise or excessive muscle use, most people express pain, discomfort, or unpleasantness within 12-24 $\mathrm{h}$ and these symptoms are called delayed onset muscle soreness (DOMS) (Cannavino et al., 2003). DOMS is one of inflammatory reaction after microdamage of primary muscle, and it is reported that it is more likely to be caused especially by eccen- tric exercises (Jung et al., 2000).

DOMS has various symptoms such as pain, tenderness, stiffness, edema, muscle weakness, and discomfort in gait (Zainuddin et al., 2005). These facilitate damage of muscle and connective tissue, and result in more decrease of muscular strengthening, range of motion, performance, and activities of daily living (Peters et al., 2003). Many researchers investigated various intervention to treat DOMS such as low-intensity warm-up before exercise and cooldown after exercise, cryotherapy, electrotherapy, and massage. Cryotherapy controls DOMS by suppressing edema (Kim et al., 2007), and transcutaneous electrical nerve stimulation which is most used clinically for pain treatment, is effective for pain-killing and range of motion improvement (Park, 2002). Moreover, massage controls pain and has biological and psychological advantages that help tissue recovery (Sluka and Wright, 2001). It is treatment for prevention and recovery of muscle fatigue (Oh et al., 2003).
${ }^{*}$ Corresponding author: Yun-Hee Sung

Department of Physical Therapy, College of Natural Sciences, Kyungnam University, 7 Kyungnamdaehak-ro, Masanhappo-gu, Changwon 631-701, Korea Tel: +82-55-249-6334, Fax: 0505-999-2173, E-mail: sungpt97@kyungnam.ac.kr Received: April 10, 2014 / Accepted: April 21, 2014
This is an Open Access article distributed under the terms of the Creative Commons Attribution Non-Commercial License (http://creativecommons.org/licenses/by-nc/3.0/) which permits unrestricted non-commercial use, distribution, and reproduction in any medium, provided the original work is properly cited. 
Among these, massage helps recovery of physical performance, promotes blood and lymph circulation, and increases joint flexibility. Especially, muscle imbalance caused by DOMS is recovered through massage and rest (Chung et al., 1993; Moraska, 2013). These effects of a massage are due to supply necessary oxygen or nutrients by eliminating waste, lactic acid (Oh et al., 2003).

However, although massage has positive effects, effect of massage related gait alteration after DOMS is still unclear. In fact, most people who have DOMS complain about unnatural gait and pain at the same time. In this study, we investigated whether massage is effective to gait and pain in participants with DOMS after excessive exercise.

\section{METERIALS AND METHODS}

\section{Participants}

This research was carried out at K University, located in Gyungsangnam-do, to 21 attending college students who agreed to the research from 2012, June 23rd to 29th.

We received informed consent from all participants after explaining their rights and the experimental process. We selected the participants who did not regularly have lower-leg exercise, and not had orthopedic disease, operation, open wound or inflammation in lower leg. As well as, we excluded participants who have hypersensitivity, or cardiopulmonary disease. General characteristics of participants are shown below (Table 1).

\section{Study design}

Participants were randomly separated into control group and experiment group. In order to cause DOMS to participants, isotonic exercises such as 20 repetitions in 5 -story building were performed, and $3 \mathrm{~min}$ of break was given after every 5 th repetition. To experiment group, massage consists of light stroking, milking, friction, and skin rolling. It was executed to gastrocnemius for 15 min. To control group, TENS equipment pad was attached to gastrocnemius for 15 min but actual treatment was not performed. After all experiments, control group received therapy for reducing pain from physiotherapist. Therapeutic mediation for control group and experiment group were performed on the same day. We chose gastrocnemius of dominant leg to measure effect of massage. The dominant leg was chosen as leg to kick the ball in front of $3 \mathrm{~m}$.

\section{Algometer}

Sensitivity of pain on gastrocnemius was measured by Commander Algometer (JTECH Medical, UT, USA). It was measured from $2 \mathrm{~cm}$ away in the midline of gastrocnemius belly. The positions were marked with surgical pen to keep constant positions for second measurements. The pressure was given until the participants complain of pain. The unit of measurement was recorded as $\mathrm{kg} / \mathrm{cm}^{2}$. The lesser unit showed the more sensitivity to pain.

\section{Gait}

To analyze the time and spatial variables of gait, Gaitrite Electronic Walkway (CIR System Inc., USA) was used. The participants walked fixing $15^{\circ}$ higher than normal eyesight with verbal cue of tester located in front of $3 \mathrm{~m}$.

\section{Statistical analysis}

The results are presented as the mean \pm standard deviation (SD). We used independent t-test for relation between groups. Correlations of gait and pain were analyzed by Spearman's correlation. All statistical analyses used IBM SPSS version 20.0. We considered statistically significant differences at $P<0.05$. All tests executed 3 time, we chose the average of 3 times.

\section{RESULTS}

\section{Changes of pain after massage-treated}

We measured pain in muscle belly of the medial and lateral gastrocnemius using Algometer. We found that change of pain on medial gastrocnemius and lateral gastrocnemius after massagetreated was significantly difference $(P<0.05)$ (Table 2 ). These show that massage on gastrocnemius after DOMS may reduce pain at gastrocnemius.

Table 1. General characteristics of the participants

\begin{tabular}{lccccc}
\hline Group & Age $(\mathrm{yr})$ & Height $(\mathrm{cm})$ & Weight $(\mathrm{kg})$ & \multicolumn{2}{c}{ Sex } \\
\cline { 4 - 5 } & & & \multicolumn{2}{c}{ Male } & $\mathrm{n}=9$ \\
Experimental $(\mathrm{n}=11)$ & $20.6 \pm 1.6$ & $169.6 \pm 8.9$ & $62.2 \pm 8.9$ & $\mathrm{n}=6$ & $\mathrm{n}=2$ \\
Control $(\mathrm{n}=10)$ & $20.9 \pm 1.7$ & $170.3 \pm 7.4$ & $66.0 \pm 10.7$ & & \\
\hline
\end{tabular}

Values are presented as number or mean \pm standard deviation. 


\section{Change of gait after massage-treated}

We confirmed change in time and spatial variables of gait using gaitrite. In the temporal variables, there was statistically differences in ambulation, heel on off time, and stride velocity $(P<0.05)$ but there were no differences in step time, cycle time, swing time, stance time, single support time, double support time. In the spatial variables, there were statistically differences in distance, step length, and stride length $(P<0.05)$ (Table 3$)$. These show that

Table 2. The change of pain after massage-treated

\begin{tabular}{lcccc}
\hline & Control & Experimental & $\mathrm{t}$ & $P$ \\
\hline MG & $29.90 \pm 21.27$ & $52.72 \pm 26.33$ & 3.07 & 0.00 \\
LG & $38.85 \pm 10.28$ & $70.95 \pm 38.89$ & 3.58 & 0.00 \\
\hline
\end{tabular}

Values are presented as number or mean \pm standard deviation. MG, medial gastrocnemius; $L G$, latreral gastrocnemius. massage on gastrocnemius after DOMS may have influence on alteration of gait pattern.

\section{Correlation of pain and gait}

As can be seen in Table 4, presents the correlations between pain and gait. In experimental group, pain on lateral gastrocnemius correlated with stance time $(\mathrm{r}=0.61, P<0.01)$ and double support time $(r=0.43, P<0.05)$. In control group, pain on medial gastrocnemius has relevance to heel on off time $(r=0.53, P<0.05)$. However, no significant correlations were found in the parameters between pain and gait.

\section{DISCUSSION}

DOMS induced by irregular or excessive exercise temporally

Table 3. The change of gait after massage-treated

\begin{tabular}{|c|c|c|c|c|c|}
\hline & & Control & Experimental & $\mathrm{t}$ & $P$ \\
\hline \multirow[t]{9}{*}{ Temporal variables } & Ambulation (sec) & $2.37 \pm 0.38$ & $1.98 \pm 0.38$ & -3.32 & 0.00 \\
\hline & Step time (sec) & $0.51 \pm 0.03$ & $0.52 \pm 0.04$ & 0.50 & 0.62 \\
\hline & Cycle time (sec) & $1.03 \pm 0.07$ & $1.03 \pm 0.07$ & 0.14 & 0.89 \\
\hline & Swing time (sec) & $0.39 \pm 0.02$ & $0.38 \pm 0.07$ & 0.05 & 0.78 \\
\hline & Stance time (sec) & $0.64 \pm 0.05$ & $0.65 \pm 0.08$ & 0.18 & 0.72 \\
\hline & Single support time (sec) & $0.39 \pm 0.03$ & $0.38 \pm 0.05$ & 0.58 & 0.37 \\
\hline & Double support time (sec) & $0.25 \pm 0.03$ & $0.24 \pm 0.04$ & -0.87 & 0.40 \\
\hline & Heel on off time (sec) & $0.14 \pm 0.04$ & $0.11 \pm 0.02$ & 0.01 & 0.02 \\
\hline & Stride velocity (sec) & $122.79 \pm 17.08$ & $138.15 \pm 15.41$ & 3.06 & 0.00 \\
\hline \multirow[t]{3}{*}{ Spatial variabels } & Distance $(\mathrm{cm})$ & $282.90 \pm 18.61$ & $253.15 \pm 15.41$ & -4.66 & 0.00 \\
\hline & Step length (cm) & $62.33 \pm 7.18$ & $68.08 \pm 2.69$ & 3.50 & 0.00 \\
\hline & Stride length (cm) & $124.47 \pm 14.45$ & $137.66 \pm 8.52$ & 3.64 & 0.00 \\
\hline
\end{tabular}

Values are presented as number or mean \pm standard deviation.

Table 4. Correlations of pain and gait

\begin{tabular}{|c|c|c|c|c|c|}
\hline & & \multicolumn{2}{|c|}{ Control } & \multicolumn{2}{|c|}{ Experimental } \\
\hline & & LG & $M G$ & LG & MG \\
\hline \multirow[t]{9}{*}{ Temporal parameters } & Ambulation (sec) & -0.15 & -0.13 & 0.17 & -0.21 \\
\hline & Step time (sec) & 0.05 & 0.25 & 0.19 & 0.11 \\
\hline & Cycle time (sec) & 0.08 & 0.28 & 0.31 & 0.07 \\
\hline & Swing time (sec) & -0.02 & 0.39 & -0.35 & 0.37 \\
\hline & Stance time (sec) & 0.12 & 0.21 & $0.61^{* *}$ & -0.25 \\
\hline & Single support time (sec) & 0.06 & 0.38 & -0.41 & 0.39 \\
\hline & Double support time (sec) & 0.22 & 0.07 & $0.43^{*}$ & -0.25 \\
\hline & Heel on off time (sec) & -0.18 & $-0.53^{*}$ & 0.36 & $0.55^{*}$ \\
\hline & Stride velocity (sec) & 0.07 & 0.31 & -0.14 & -0.15 \\
\hline \multirow[t]{3}{*}{ Spatial parameters } & Distance (cm) & 0.00 & 0.17 & -0.35 & 0.00 \\
\hline & Step length (cm) & 0.21 & $0.48^{*}$ & 0.10 & 0.15 \\
\hline & Stride length (cm) & 0.21 & $0.49^{*}$ & -0.20 & -0.09 \\
\hline
\end{tabular}

Values are presented as number or mean \pm standard deviation. $M G$, medial gastrocnemius; $L G$, latreral gastrocnemius. ${ }^{*} P<0.05$. ${ }^{* *} P<0.01$. 
produces immoderate metabolites like lactic acid. These result in inappropriate blood supply and lack of oxygen in contracting muscle, then cause pain, muscle weakness, decline of ROM, and reduction of proprioceptive sense (Cheung et al., 2003; Choi and Nam, 2004). Among these, pain is not only the main symptom but also important standard to decide the effectiveness of treatment (Kim et al., 2004). Kim (2005) confirmed the change of pain after massage-treated to patients with gout. Oh (2006) reported that sports massage program is an effective treatment to reduce pain in patients with DOMS. Hilbert et al. (2003) assessed pain at 2, 6, 24, and $48 \mathrm{~h}$ after DOMS. They also reported that massage decreased the intensity of soreness at $48 \mathrm{~h}$ after muscle insult. Measuring the intensity of pain plays important component to decide the therapeutic effect. Most researchers use visual analogue scale (VAS) as pain assessment tool. Although VAS is an easy tool for self-report of pain, in many cases, it has tendency to check in the midline between maximum and minimum. De Jong et al. (2005) showed that VAS has a poor intra-rater reliability and inter-rater reliability in some target group. So, we used digital algometer to more objectively prove the change of pain. In this study, we also showed that massage on gastrocnemius after DOMS affects pain reduction. These mean that massage on gastrocnemius is valuable as intervention to relieve pain induced by DOMS.

Gait is one of the most basic movements in performing daily tasks. During gait, at the stance time, the support of lower extremity must be maintained, and at the swing time, the foot must be completely off the ground (Den Otter et al., 2007). Gait can be checked by many parameters such as step time, cycle time, heel on off time, step length, stride velocity, and so on (McDermott et al., 2010). Especially, the gait velocity is used as an important parameter to assess the motor function or the quality of life after disease (Jonsdottir et al., 2009). In our study, we confirmed that massage on gastrocnemius after DOMS increases stride velocity, step length, stride length, ambulation, heel on off time, distance. It means that our intervention has effect on gait problem cause by DOMS. These changes may due to location of applied massage. Problems of gastrocnemius lead to various abnormal gait pattern (Wang et al., 2014). Many researches demonstrated that the stimulation of plantar flexor such as gastrocnemius to patients with stroke or cerebral palsy improves gait velocity, stride length, and cadence (Damino and Abel, 1998; Kim et al., 2007; Teixeira-Salmela et al., 2001). We confirmed correlation between pain and gait. Whereas pain after DOMS increased the heel on off time, and shortened step and stride length, massage on gastrocnemius has influence on stance time, double support time, and heel on off time. We can suppose that massage on gastrocnemius help recovery of pathologic gait by controlling pain after DOMS.

Massage helps blood and lymph circulation, and eliminates lactate accumulation by inflammation or fatigue. As well as, it reduces edema affecting the exchange of tissue fluid (Sedergreen, 2000; Tanaka et al., 2002). Crane et al. (2012) induced DOMS to quadriceps and performed biopsy after massage. They reported that the production of tumor necrosis factor- $\alpha$ (TNF- $\alpha$ ) and interleukin- 6 (IL-6) was reduced by massage. Cytokines such as TNF- $\alpha$ and IL-6 were increased by inflammation. Many researchers have interest in intervention to alleviate inflammation like nonsteroidal anti-inflammatory drugs. Massage may have influence on inflammatory process like anti-inflammatory medicine. Anti-inflammatory effect of massage has relevance to control of pain (Moraska, 2013). We also found that massage on gastrocnemius after muscle damage alleviate pain. Alteration of pain will be due to anti-inflammatory effect of massage.

According to this study, massage on gastrocnemius after DOMS may decrease pain caused by fatigue and inflammation, and pain reduction may lead to change of gait. Therefore, the massage on gastrocnemius after DOMS can be used as effective therapeutic mediation facilitating recovery of pain and gait.

Lastly, this research did not confirm central fatigue after DOMS and was not able to perform gastrocnemius biopsy obtaining objective evidence to confirm biochemical effects. Further on, we will continue researches not only phenomenological effects following approach of massage time, method, and area but also biochemical effects. Furthermore, we will study effects of massage on patient with nervous system and musculoskeletal problem.

\section{CONFLICT OF INTEREST}

No potential conflict of interest relevant to this article was reported.

\section{REFERENCES}

Cannavino CR, Abrams J, Palinkas LA, Saqlimbeni A, Bracker MD. Efficacy of transdermal ketoprofen for delayed onset muscle soreness. Clin J Sport Med 2003;13:200-208.

Cheung K, Hume P, Maxwell L. Delayed onset muscle soreness: treatment strategies and performance factors. Sports Med 2003;33:145-164.

Choi KH, Nam SN. Effects of the eccentric exercise induced delayed muscle soreness on proprioception, muscle strength and muscle fatigue. J Korea Soc Phys Ther 2004;16:176-191. 
Chung HK, Choi JH. A study of the effects of massage on hamstring muscles extensibility. J Korea Soc Phys Ther 1993;5:3-8.

Crane JD, Oqborn DI, Cupido C, Melov S, Hubbard A, Bourqeois JM, Tarnopolsky MA. Massage therapy attenuates inflammatory signaling after exercise-induced muscle damage. Sci Transl Med 2012;4:113119.

Damino DL, Abel MF. Functional outcomes of strength training in spastic cerebral palsy. Arch Phys Med Rehabil 1998;79:119-125.

De Jong AE, Bremer M, Schouten M, Tuinebreijer WE, Faber AW. Reliability and validity of the pain observation scale for young children and the visual analogue scale in children with burns. Burns 2005;31: 198-204.

Den Otter AR, Geurts AC, Mulder T, Duysens J. Abnormalities in the temporal patterning of lower extremity muscle activity in hemiparetic gait. Gait Posture 2007;25:342-352.

Hilbert JE, Sforzo GA, Swensen T. The effects of massage on delayed onset muscle soreness. Br J Sports Med 2003;37:72-75.

Jonsdottir J, Recalcati M, Rabuffetti M, Casiraqhi A, Boccardi S, Ferrarin $M$. Functional resources to increase gait speed in people with stroke: strategies adopted compared to healthy controls. Gait Posture 2009;29: 355-359.

Jung YJ, Go SJ, Yu HY, Jung DY. Effects of transcutaneous electrical nerve stimulation and microcurrent electrical neuromuscular stimulation on delayed onset muscle soreness. Phys Ther Korea 2000;7:76-87.

Kim HR, Rue EM, Sin HJ. Effect of myofascia massage on reduction of myalgia and muscle relaxation and recovery of delayed onset muscle soreness (DOMS) of lower body. Korea J Aesthet Cosmetol 2012;10:5159.

Kim JM, Park JS, Kim WH, Cynn HS, Kim YJ. The effect of hold-relax technique and cryotherapy on delayed onset muscle soreness. Phys Ther Korea 2007;7:22-31.

Kim JT, Park SH. The effect of arm sling on the lower extremity muscle activity during hemiplegia patient's walking stance phase. Korea J Phys Educ 2007;46:713-722.

Kim YB. Effects of pain rating scale in the massage program on gout. Korea Soc Sports Sci 2005;28:29-43.

Kim YB, Park BG, Jung DH. Effects of pain rating scale in the therapeutic massage program on fibromyalgia syndrome. Korea Soc Sports Sci 2004;27:61-79.

McDermott A, Bolger C, Keating L, Keating L, McEvoy L, Meldrum D. Reliability of three-dimensional gait analysis in cervical spondylotic myelopathy. Gait Posture 2010;32:552-558.

Moraska A. Massage efficacy beliefs for muscle recovery from a running race. Int J Ther Massage Body Work 2013;6:3-8.

Oh DW. The effects of sports massage program on the pain and indicators of muscle damage in delayed onset muscle soreness. Korea Sport Res 2006;17:225-244.

Oh HS, Jung DH, Oh DW. The effects of therapeutic sports massage and ultrasound therapy on delayed onset muscle soreness. Korea Sport Res 2003;14:1905-1920.

Park JS. The effects of transcutaneous electrical nerve stimulation on sympathetic nerve activity in delayed onset muscle soreness. J Korea Soc Phys Ther 2002;14:109-115.

Peters D, Barash IA, Burdi M, Yuan PS, Mathew L, Fridén J, Lieber RL. Asynchronous functional, cellular and transcriptional changes after a bout of eccentric exercise in the rat. J Physiol 2003;15:947-957.

Sedergreen C. Is massage therapy genuinely effective? CMAJ 2000;163: 953-954.

Sluka KA, Wright A. Knee joint mobilization reduces secondary mechanical hyperalgesia induced by capsaicin injection into the ankle joint. Eur J Pain 2001;5:81-87.

Tanaka TH, Leisman G, Mori H, Nishijo K. The effect of massage on localized lumbar muscle fatigue. BMC Complement Altern Med 2002;2:1-9.

Teixeira-Salmela LF, Nadeau S, Mcbride I, Olney SJ. Effects of muscle strengthening and physical conditioning training on temporal, kinematic and kinetic variables during gait in chronic stroke survivors. J Rehab Med 2001;33:53-60.

Wang XY, Kang WY, Yang Q, Zhanq LY, Chen SD, Liu J. Using gastrocnemius sEMG and plasma $\alpha$-synuclein for the prediction of freezing of gait in Parkinson's disease patients. PLoS One 2014;27:9:e89353.

Zainuddin Z, Newton M, Sacco P, Nosaka K. Effects of massage on delayed-onset muscle soreness, swelling, and recovery of muscle function. J Athl Train 2005;40:174-180. 